\title{
ANTICANCER STUDY OF MYRISTICA FRAGRANS HOUTT. (MACE) EXTRACT ON 4-NITROQUINOLINE-1-OXIDE-INDUCED ORAL CANCER IN RATS
}

\author{
GAYATHRI R ${ }^{1,2 *}$, ANURADHA VENKATARAMAN ${ }^{3}$, VISHNUPRIYA V ${ }^{2}$, MALLIKA JAINU ${ }^{4}$
}

${ }^{1}$ Department of Biochemistry, Research and Development Centre, Bharathiyar University, Coimbatore - 641 106, Tamil Nadu, India. ${ }^{2}$ Department of Biochemistry, Saveetha Dental College and Hospital, Saveetha Institute of Medical \& Technical Sciences, Saveetha University, Velappanchavadi, Chennai - 600 077, Tamil Nadu, India. ${ }^{3}$ Department of Biochemistry, Mohammed Sathak College of Arts and Science, Sholinganallur, Chennai - 600 119, Tamil Nadu, India. ${ }^{4}$ Department of Biochemistry, Biogen Care Research Center, Chennai - 600 014, Tamil Nadu, India. Email: gayathri.jaisai@gmail.com

Received: 19 February 2018, Revised and Accepted: 03 April 2018

\section{ABSTRACT}

Objective: Oral cancer is the most common forms of malignancy diagnosed in men and women and the mortality rate is very high in the developing countries. Therefore, the study was conducted to evaluate the potential role of Myristica fragrans Houtt (mace) acetone extract (MAE) on experimentally induced oral cancer in rats.

Methods: Oral cancer was experimentally induced to rats by administering 4NQO (carcinogenic agent) at a concentration of 30 ppm in drinking water and treated with three different doses of mace extract $(100,250,500 \mathrm{mg} / \mathrm{kg}$ body weight) dissolved in water and given orally as a single dose and another group treated with the standard 5-fluorouracil for 14 weeks.

Results: All the experimental groups had an incremental weight gain, except NQO alone induced group showed body weight loss and also showed low survival rate denoting the NQO carcinogenic toxicity in them. The exophytic tumor volume showed gradual increase and reached 30 mm 3 at the 14 weeks time point. Tumor incidence and tumor multiplicity values of mace extract treatment (100, 250, 500 mg/kg body weight) showed gradual reduction in the size of tumor significantly compared with that of the standard drug. The histopathological examination of oral tumor mucosal tissue illustrated well differentiated squamous cell carcinoma in NQO induced group and also declining the risk of carcinoma changes in MAE treated groups.

Conclusions: These experimental results unveil that MAE possesses effective role in curing oral cancer.

Keywords: Oral cancer, 4-nitroquinoline-1-oxide, Myristica fragrans Houtt., Histopathology.

(c) 2018 The Authors. Published by Innovare Academic Sciences Pvt Ltd. This is an open access article under the CC BY license (http://creativecommons. org/licenses/by/4. 0/) DOI: http://dx.doi.org/10.22159/ajpcr.2018.v11i7.25363

\section{INTRODUCTION}

Oral cancer is the sixth most common cancer affecting humankind, which also presents with a low rate of survival. Above $90 \%$ of oral cancers are histopathologically squamous cell carcinomas (SCCs) [1]. The migration of oral SCC into maxillary and mandibular bones is a typical clinical problem [2]. Oral SCCs commonly affect males over 40 years of age with a history of regular exposure to etiological risk factors such as alcohol, tobacco products, betel quid, or micronutrient deficiency. Current research showed that even younger patients with lower cumulative tobacco or alcohol exposure are prone to OSCC [3]. The location of OSCC is at the base of the tongue, tonsils, and oropharynx and associated with human papillomavirus [3]. The current standard approach of medicine for the treatment of oral cancer consists of attempts to eradicate established tumor with combined treatment, such as surgery, chemotherapy, and radiation. However, these therapies have failed in many aspects making human life pathetic and reducing the lifespan of patients, and also after surgical treatment, there will be a distortion of face and trouble in breathing, swallowing, and speaking. Patients remain sick, due to noxious effect of radiation and chemotherapies as these cells not only kill cancer cells but also kill normal cells. This makes patients suffering from various diseases along with opportunistic infections [4].

The National Cancer Institute collected about 35,000 plant samples collected from 20 different countries and has screened around 114,000 extracts for anticancer activity [2]. They reported that over 3000 species of plants have antitumor properties [5]. Therefore, the need of the hour is to develop treatment modalities using plant derivatives which ambiguous potent side effects and act as effective therapeutic agents [6]. The animal models permit the development and testing of new way to disease prevention, treatment, and identification of early diagnostic markers and novel therapeutic targets, and it is the best studied that rat model mimics the same clinical features as human SCCs. This model is useful because of a close similarity to human oral carcinogenesis at both histological and molecular levels.

Mace is the aril part on the kernel of Myristica fragrans Houtt. (family: Myristicaceae), an evergreen aromatic tree cultivated in many tropical countries, and is widely used as a spice and also to flavor many kinds of baked foods and vegetables [7]. Mace composed of a maximum number of plant constituents mainly alkyl benzene derivatives (myristicin, elemicin, safrole, etc.), terpenes, alpha-pinene, beta-pinene, myristic acid, trimyristin, neolignan (myrislignan), and mace lignin [7]. The chemical constituents of mace have been investigated by scientists for hypolipidemic, hypocholesterolemic, antimicrobial, antidepressant, aphrodisiac, memory-enhancing, antioxidant, and hepatoprotective properties [8]. Mace is widely used as a flavoring agent, a hair dye, and a folk medicine. It also possesses anti-papilloma genic, anticarcinogenic, chemopreventive, and anti-inflammatory activities [7,9]. In dentistry application, macelignan, an active compound from $M$. fragrans Houtt., had strong anticarcinogenic activity and antibacterial effect [8].

The previous study in our laboratory proved the efficacy of acetone mace extract on human oral carcinoma KB cells which served as the 
backdrop for our current work. Therefore, the study was conducted to evaluate the potential role of $M$. fragrans Houtt. (mace) acetone extract (MAE) on oral cancer in rats by monitoring the body weight, tumor volume, tumor growth, and histopathological examination of oral mucosal tissue.

\section{METHODS}

The authenticated sample of dried mace of $M$. fragrans Houtt. was procured from the Herbal Care and Cure Centre (Chennai, India), and the sample was identified with the help of a botanist at the Central Drug Research Institute, Chennai, before the study was carried out. All other chemicals used for this study were of analytical grade purchased from Sigma Aldrich Company, USA.

\section{Extraction}

The dried powder sample of mace $(80 \mathrm{~g})$ was extracted 3 times by hot percolation method with 1:5 ratio volume of acetone at room temperature for $72 \mathrm{~h}$. The filtrates were concentrated under reduced pressure at $40^{\circ} \mathrm{C}$ and stored at room temperature for use in subsequent experiments [10].

\section{Animals}

Specific and pathogen-free Wistar strain rats were chosen for this study. They were obtained and acclimatized to laboratory environment. They were housed in polypropylene cages with stainless steel grid covers, and bedding material used is paddy or wheat husk. They were groomed in a controlled environment with feed and drinking water provided in polypropylene bottles. Experimental protocols were approved by the Institutional Animal Ethics Committee (IAEC), which follows the guidelines of Committee for the purpose of control and supervision of experiment on Animals and the Guide for the care and use of laboratory animals. The IAEC approval number for this study: SU/CLAR/ $\mathrm{RD} / 030 / 2017$.

\section{Test compound and dose administration levels}

Anticarcinogenic test is performed in accordance to the guidelines of the World Health Organization (WHO 2000) and the Organization of Economic Co-operation and Development (OECD) guideline for testing of chemicals (OECD, 2001). Oral cancer was induced in rats using 4-nitroquinoline-1-oxide (4NQO) as a carcinogenic agent. Drinking water containing NQO was freshly prepared every week in deionized water and was administered to the rats in light-shielded water bottles.

Group I served as normal control.

Groups II, III, IV, V, and VII receive 4NQO at a concentration of $30 \mathrm{ppm}$ in their drinking water for 14 weeks.

Groups III, IV, and V served as treatment groups and received mace extract at the doses of 100,250 , and $500 \mathrm{mg}$ per kg body weight orally as a single dose for 14 weeks retrospectively.

Group II served as the carcinoma control group and received only 4NQO at the concentration of $30 \mathrm{ppm}$ in drinking water for 14 weeks without any treatment.

Group VI is treated with 5-flourouracil (5FU) at a concentration of $50 \mathrm{mg} / \mathrm{kg}$ body weight orally as a single dose.

Group VII served as drug control, rats treated with mace extract ( $250 \mathrm{mg} / \mathrm{kg}$ body weight) as a single dose for 14 weeks.

The body weight, tumor growth, and tumor volume were measured during the experimental period. After the completion of treatment period, the animals were sacrificed using overdose of anesthesia and oral cavity tissue was collected for carrying out histology. The experiment was terminated at 14 weeks after the start, and all animals were killed to assess the incidences of tumor.

\section{Tumor volume}

The initial measurement of a volume of exophytic tumor was done after 8 weeks following the start of the experimental procedure. By measuring the size of the tumor in three dimensions, the volume was calibrated in $\mathrm{mm}^{3}$ using the following formula: $\mathrm{V}=\mathrm{l} \times \mathrm{w} \times \mathrm{h}$. After 14 weeks, the average volume was $6 \mathrm{~mm}^{3}$ with a range of 2-12 $\mathrm{mm}^{3}$. Gradually with time, the volume increased and reached $30 \mathrm{~mm}^{3}$ at the 14 weeks' time point.

\section{Tumor growth}

Body weight was regularly checked to determine $4 \mathrm{NQO}$ toxicity. On the next day, after the final treatment, the animals were sacrificed and the solid tumors were excised for further analysis. The tumor growth was evaluated using a caliper and the tumor volume $(V)$ was calculated using the following formula described by Carlsson: $V=(a b 2) / 2$, where "a" is the longest diameter and "b" is the shortest diameter of tumor.

\section{Histological examination}

After the fixation of oral mucosal tissue in formal saline $(10 \%)$ for $24 \mathrm{~h}$, the tissue was subjected to dehydration using series of alcohols (methyl, ethyl, and absolute ethyl alcohol) followed by embedding in paraffin wax at $56^{\circ} \mathrm{C}$. After that, the wax tissue blocks were sectioned by sliding microtome and then prepared for the histological slide examination using hematoxylin and eosin stain and viewed under the light electric microscope (Olympus Cx21 with attached digital camera).

\section{RESULTS}

Effect of mace extract on body weight changes in oral cancerinduced rats

The extract of mace exhibited a dose-dependent significant body weight gain $(\mathrm{p}<0.05)$ in the groups treated with $100 \mathrm{mg} / \mathrm{kg}, 250 \mathrm{mg} / \mathrm{kg}$, and $500 \mathrm{mg} / \mathrm{kg}$ of mace extract as compared to 4NQO-induced groups. All the experimental groups had an incremental weight gain at the end of the experimental period, whereas Group II animals (4NQO) alone showed a decrease in weight indicating the cancer induced in them. The groups treated with $500 \mathrm{mg} / \mathrm{kg}$ body weight of mace extract showed the body weight increase when compared to 100 and $250 \mathrm{mg} / \mathrm{kg}$ of macetreated groups. The Group VII mace extract ( $250 \mathrm{mg} / \mathrm{kg}$ body weight) served as a drug control showed no weight reduction when compared to control groups, and this proved the absence of drug toxicity by mace. However, the different doses of MAE had an incremental weight gain at the end of the experimental period (Table 1).

Effect of mace extract on tumor incidence and tumor multiplicity Figs. 1 and 2 display the levels of tumor incidence in experimental animals. Assessment of tumor incidence and tumor multiplicity in various experimental groups revealed that there was a significant $(\mathrm{p}<0.05)$ increase in the tumor levels. Group II (4NQO) alone induced group has shown the highest level of tumor incidence and tumor multiplicity when compared with control rats. The different doses of mace extract $(100 \mathrm{mg} / \mathrm{kg}, 250 \mathrm{mg} / \mathrm{kg}$, and $500 \mathrm{mg} / \mathrm{kg}$ )-treated groups showed the decrease level of tumor incidence and tumor multiplicity compared to 4NQO. Mace extract and 5-flourouracil treated groups

Table 1: Effect of mace extract on body weight changes

\begin{tabular}{llll}
\hline Groups & \multicolumn{2}{l}{ Body weight $(\mathrm{g})$} & Survival \\
\cline { 2 - 3 } & Initial & Final & \\
\hline Group I & $175 \pm 10.1$ & $200 \pm 5.1$ & $6 / 6$ \\
Group II & $170 \pm 9.4$ & $160 \pm 4.8^{*}$ & $3 / 6$ \\
Group III & $175 \pm 8.1$ & $180 \pm 8.6^{\mathrm{a}}$ & $4 / 6$ \\
Group IV & $170 \pm 4.7$ & $185 \pm 7.4^{\mathrm{b}}$ & $6 / 6$ \\
Group V & $170 \pm 2.6$ & $190 \pm 6.9^{\mathrm{c}}$ & $6 / 6$ \\
Group VI & $170 \pm 1.4$ & $190 \pm 8.1^{\mathrm{c}}$ & $6 / 6$ \\
Group VII & $175 \pm 1.1$ & $200 \pm 10.7$ & $6 / 6$ \\
\hline
\end{tabular}

Data represent the means \pm SEM, $n=6 .{ }^{*} \mathrm{p}<0.001$, statistically significant as compared with control rats and ${ }^{\mathrm{a}} \mathrm{p}<0.05,{ }^{\mathrm{b}} \mathrm{p}<0.01$, and ${ }^{\mathrm{c}} \mathrm{p}<0.001$, statistically significant as compared with Group II rats. SEM: Standard error of mean 
showed declined total tumor and large tumor $(2-10 \mathrm{~nm})$ numbers when compared with 4-NQO alone treated group. Mace extract reverted the changes more or less like the 5 -flourouracil standard group when compared to their respective untreated group.

\section{Histopathological examination of oral mucosal tissue}

Fig. 3 shows the histology of changes in mace extract-treated and untreated oral mucosal cancer tissues. The oral mucosal tissue from



Fig. 1: This graph depicts the effect of different doses of mace extract on a number of tumors. Data represent the means \pm SEM, $\mathrm{n}=6 .{ }^{*} \mathbf{p}<0.001$, statistically significant as compared with control rats and ${ }^{\mathrm{a}} \mathrm{p}<0.05,{ }^{\mathrm{b}} \mathrm{p}<0.01$, and ${ }^{\mathrm{c}} \mathrm{p}<0.001$, statistically significant as compared with 4-nitroquinoline-1-oxide-induced rats. SEM: Standard error of mean

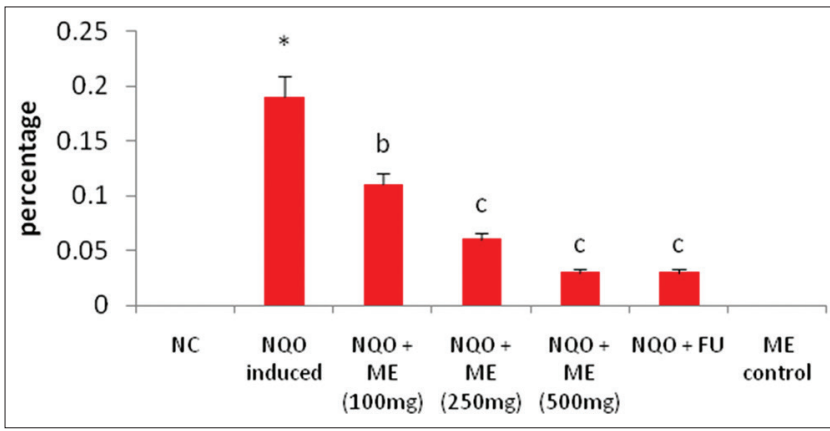

Fig. 2: This graph depicts the effect of different doses of mace extract on tumor multiplicity. Data represent the means \pm SEM $\mathrm{n}=6$. ${ }^{*} \mathbf{p}<0.001$, statistically significant as compared with control rats and $d^{b} p<0.01$ and $^{c} p<0.001$, statistically significant as compared with 4-nitroquinoline-1-oxide-induced rats. SEM: Standard error of mean
4NQO-induced rats (Fig. 3b) revealed well-differentiated SCC, a tumor which consists of irregular masses of epidermal cells. The mace extract-treated (Fig. 3c-e) rats showed moderate risk of oral epithelial dysplasia, less risk of oral cell carcinoma, and reduced risk of carcinoma changes with the increasing dosage levels $(100 \mathrm{mg} / \mathrm{kg}, 250 \mathrm{mg} / \mathrm{kg}$, and $500 \mathrm{mg} / \mathrm{kg}$ ), respectively, when compared to untreated groups. On treatment with 5 -flourouracil, the standard drug showed very less risk of carcinoma changes (Fig. 3f) as similar to that of high dose of mace treated carcinogenic rats. Whereas, mace extract alone treated groups showed intact normal mucosal architecture with no toxicity changes.

\section{DISCUSSION}

The discovery and development of chemotherapeutics that are effective for the treatment and control of oral cancer are urgently needed. Natural products are still important sources to discover new anticancer drugs. Several studies have revealed that certain naturally occurring medicinal plants inhibit the growth of various cancers [11]. The methanol extract of $M$. fragrans exhibited good potential as antimicrobial, antioxidant, and anticancer agents [12]

The impact of mace extract on body weight showed a marked increase in experimental rats as compared to control rats even after the administration of 4NQO. Whereas, Group II animals alone showed a decrease in weight indicating the cancer induction in rats. On treatment with mace extract, the body weight was significantly increased as similar to that of normal group.

The typical tumor progression for SCC was seen before invasive SCCs appeared. The assessment of tumor incidence and tumor multiplicity in various experimental groups revealed that there was a significant increase in the tumor levels in NQO-induced group when compared with normal control and mace-treated rats. The extract treatment proved that the number of tumors and tumor multiplicity had declined gradually according to low to high dose whereas similar results were observed in 5-flourouracil treated group. The mace extract reverted the changes near normal levels more or less like the 5FU standard drug group when compared to their respective untreated group. Mace lignan showed antibacterial property against Streptococcus mutans which is an oral pathogen causing dental caries [13] which supports the present findings.

The morphology of SCC can vary greatly. Thus, the tumor may often be more differentiated at the surface of the lesion than in the deeper, invasive part [14]. The classification of SCC is based on the differentiation or maturation of the tumor cell population without consideration of the tumor-host relationship [15]. The high grading of OSCC reflects the growth capacity and malignancy of the tumor and in predicting the outcome of the disease at an early stage $[16,17]$

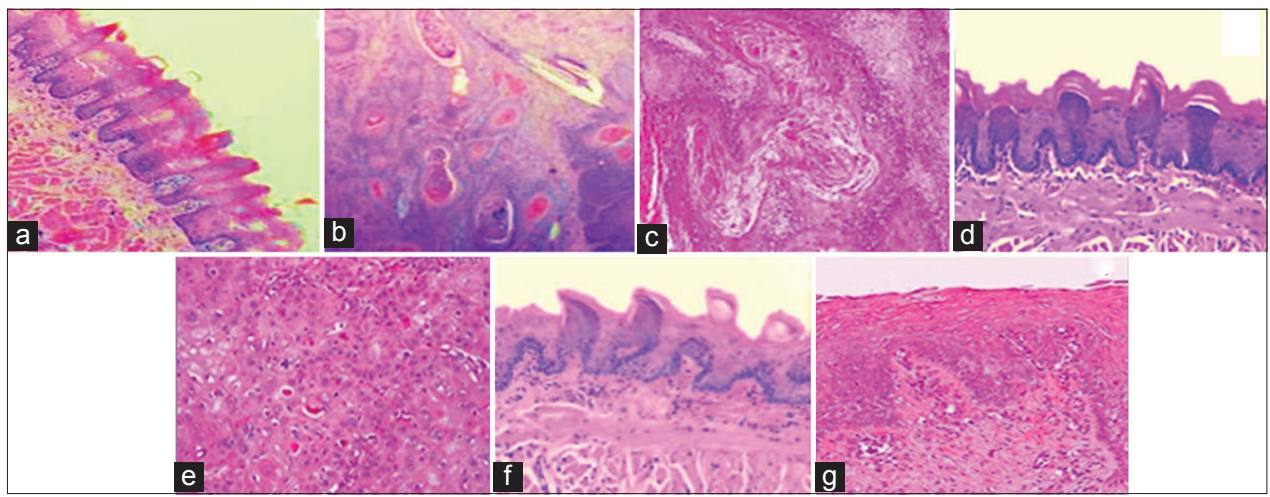

Fig. 3: Histopathology of oral mucosal tissue. (a) Normal control, (b) 4-nitroquinoline-1-oxide (NQO) induced, (c) NQO + Myristica fragrans Houtt (mace) acetone extract (MAE) $(100 \mathrm{mg})$, (d) NQO + MAE (250 mg) (E) NQO + MAE (500 mg) (F) NQO + flourouracil, and (G) MAE control 
Well-differentiated SCC is a tumor which consists of irregular masses of epidermal cells which show decreased dermal proliferation [18]. The histopathological results revealed that oral mucosal tissue from 4NQO alone induced rats revealed well-differentiated SCC. The 5FU-treated group showed a reduced risk of carcinoma changes when compared to 4NQO alone treated group. Moreover, different doses of extract-treated group rats showed the moderate risk of oral epithelial dysplasia, less risk of oral cell carcinoma, and reduced risk of carcinoma changes with the increasing dosage levels, respectively, when compared to untreated groups. Our histological results showed a progressive decrease in risk of oral squamous carcinoma across the group with increase in doses of extract-treated group. Therefore, the inhibition of tumor growth in oral cavity by mace extract might be due to the presence of several bioactive constituents which possess antiproliferative and anticancer actions, and the presence of lignan compounds exhibited chemopreventive and cytotoxic property.

\section{CONCLUSION}

In the present study, we concluded that mace extract possesses anticancer effect by exhibiting a reduced percentage of tumor incidence in oral cancer-induced rats. In addition, further studies are needed to be characterize that bioactive compounds are responsible for the observed activities of mace plant as a novel resource for new anticancer drugs and these results put forward an attempt to carry out trials on human beings.

\section{AUTHOR'S CONTRIBUTION}

All the authors contributed equally to planning, literature collection, animal experimental work, result analysis, and paper writing.

\section{CONFLICTS OF INTEREST}

All authors have none to declare.

\section{REFERENCES}

1. Salahshourifar I, Chog VK, Thomas G, Zain RB. Genomic DNAcopy number of alterations from precursor of oral lesions to oral squamous cell carcinoma. Oral Oncol 2014;50:404-12.

2. Sumitra C, Krunal N. In vitro and In vivo methods for anticancer activity evaluation and some Indian medicinal plants possessing anticancer properties: An overview. J Pharm Phytochem 2013;2:140-52.

3. Vu N, Camile SF. Efficacy of narrow band imaging for detection and surveillance of potential malignant and malignant lesions in the oral cancer and oropharynx. Oral Oncol 2014;50:413-20.

4. Mozaffarul I, Datta J, Teknos LT. Down regulation of RhoCby microRNA-138 results in de-activation of FAK, Src and Erik signaling pathway in head and neck squamous cell carcinoma. Oral Oncol 2014;68:448-56

5. Desai AG, Qazi GN, Ganju RK, El-Tamer M, Singh J, Saxena AK, et al. Medicinal plants and cancer chemoprevention. Curr Drug Metab 2008;9:581-91.

6. Kumar A, Rahal A, Chakraborty S, Tiwari R. Ocimum sanctum (tulsi): A miracle herb and boon to medical science: A review. Int J Agric Plant Prod 2013;4:1580-9.

7. Kim EY, Choi HJ, Park MJ, Jung YS. Myristicafragrans suppresses tumor growth and metabolism by inhibiting lactate dehydrogenase. Am J Chin Med 2016;44:1063-79.

8. Ulyana MA, Peter J, Blanco C, Susan M, Esperanza JC. New acyclic bisphenylpropanoid and neolignans, from Myristicafragrans Houtt., exhibiting PARP-1 and NF- $\kappa$ B inhibitory effects. Food Chem 2016;202:269-75.

9. Jannu LN, Hussain SP, Rao AR. Chemopreventive action of mace (Myristicafragrans, Houtt) on DMBA-induced papillomagenesis in the skin of mice. CancerLett 1991;56:59-63.

10. Gayathri R, Anuradha V. Phytochemical screening and total phenolic content of aqueous and acetone extracts of seed, butter, mace of Nutmeg (Myristicafragrans Houtt). Int J Pharm Sci Rev Res 2015;33:236-9.

11. Eun-Sun C, Jun-Sung K, Ki-Han K, Hyng-Seop K, Cho NP, Cho S. Methanol extract of Sanguisorba officinalis L. with cytotoxic activity against PC53 human prostate cancer cells. Mol Med Rep 2012;6:670-4.

12. Chakraborty P, Lavanya P, Abraham J. Bioactivity of Myristica fragrans methanol extract. World J Pharm Res 2015;4:1145-57.

13. Nagja T, Vimal K, Sanjeev A. Myristica fragrans: A comprehensive review. Int J Pharm Pharm Sci 2016;8:27-30.

14. Tang XH, Knudsen B, Bemis D, Tickoo S, Gudas LJ. Oral cavity and esophageal carcinogenesis modeled in carcinogen-treated mice. Clin Cancer Res 2004;10:301-13.

15. Wiixen R, Nathanson A, Moberger G, Anneroth G. Squamous cell carcinoma of the gingiva. Histological classification and grading of malignancy. Acta Otolaryngol 1975;79:146-54

16. Anneroth G, Hansen LS. A methodologic study of histologic classification and grading of malignancy in oral squamous cell carcinoma. Scand J Dent Res 1984;92:448-68.

17. Hasan S, Elongovan S. Conventional and advanced diagnostic aids in oral cancer screening-the journey so far. Int J Pharm Pharm Sci 2015;7:29-33.

18. Ramos J, Villa J, Ruiz A, Armstrong R, Matta J. UV dose determines key characteristics of nonmelanoma skin cancer. Cancer Epidemiol Biomarkers Prev 2004;13:2006-11. 